\title{
The Biological Agricultural Application And Extension Base on Biology Construction Project
}

\author{
Lin $\mathrm{Na}^{1}$, Du Hang ${ }^{1}$, Xing Ying Ying ${ }^{1}$, Zong YongGang ${ }^{1}$, Liu ZiHao ${ }^{1}$ \\ ${ }^{1}$ Binzhou Polytechnic, Binzhou, Shandong 256600, China \\ Email:'ㄹz3383102@163.com
}

\begin{abstract}
\section{INTRODUCTION}

At present, China is transforming from traditional agriculture to modern intelligent agriculture. The core of modern intelligent agriculture is intelligent agricultural equipment, which can greatly improve the production efficiency and quality safety of agricultural products. Therefore, vigorously developing the intelligence of agricultural equipment is the key factor to promote the development of modern intelligent agriculture. Iot of emerging technology is applied to agricultural equipment can significantly improve the intelligence of agricultural equipment, is now able to drive the modern agricultural development and key technologies of wisdom, but at present the Internet of things technology in the application of agricultural equipment is not yet mature, there are still many problems need to be solved, such as: the high cost of agricultural equipment, stability is not high, intelligent still need further enhance and so on. At present, the country attaches great importance to the research of intelligent agricultural equipment.
\end{abstract}

Main research contents and technical and economic indicators: The plan, organization, implementation and control of agricultural production and service creation in the process of digitizing agricultural elements and processes and analyzing the digital resources generated by the new Internet of Things system are adopted as the basic support system. Its goal is to achieve the precision of agricultural input-output control, build the cotton planting base into the promotion base of digital agriculture, save labor costs and reduce labor input. The big data Internet of Things and modern agriculture organic combination

Keywords: agriculture production, digitizing agricultural, basic support system

\subsection{Related Work}

At present, Cooperative has several thousand members and cotton picking area of one thousand $\mathrm{mu}$. It is large in scale but low in intelligence level. It relies on a large number of manpower and growers have a strong demand to change the production mode by relying on smart agriculture and digital agriculture. Smart agriculture is an advanced stage of agricultural production, which

integrates the emerging technologies of the Internet, mobile Internet, cloud computing and Internet of Things[1]. Relying on various sensor nodes deployed in the field of agricultural production, environmental temperature and humidity, soil moisture, carbon dioxide, image and wireless communication network to realize the agricultural production environment of intelligent early warning, intelligent decision-making, visual management, intelligent decision making. "Smart agriculture" refers to the comprehensive and comprehensive application of cloud computing, sensor network, $3 \mathrm{~S}$ and other information technologies in agriculture, so as to achieve more complete information foundation support, more thorough agricultural information perception, more concentrated data resources, more extensive interconnection, deeper intelligent control, and more considerate public services. The integration of "smart agriculture" with modern biotechnology, digital design and information management the agricultural objects, environment and the whole process. Digital agriculture makes the information technology and each link of agriculture realize the effective integration, which is of great significance to the reform and dissemination of agriculture and the transformation of agricultural production mode. Digital agriculture will be remote sensing, geographic information system, global positioning system (GPS), computer technology, communication and network technology, automation technology and other high and new technology and geography, agronomy, ecology, plant physiology, soil science and other basic subjects organically, realize in the process of agricultural production of crops, real-time monitoring of soil from macro to micro, In order to achieve the growth and development of crops, pests, water and fertilizer status and the corresponding environment for regular information acquisition, generation of dynamic spatial information system, the phenomenon in agricultural production, process simulation, reduce production costs, improve the ecological environment, improve the quality of crop products 
and purposes. Our research group designs intelligent agricultural extension base according to the needs of enterprises.

\subsection{Our Contribution}

At present, digital economy has become an important symbol to measure a country's economic strength. Research shows that the United States, as the largest economic power, has a digital economy that accounts for more than $60 \%$ of its GDP, while the United Kingdom, Germany, Japan and other advanced countries have a digital economy that accounts for more than $50 \%$ of their GDP. In 2018, the scale of China's digital economy reached 31.3 trillion yuan, ranking the second in the world, accounting for $34.8 \%$ of GDP, more than 20 percentage points behind the $60 \%$ of the United States, a relatively obvious gap.

Digital agriculture rural development has made significant achievements in our country, but at the same time, we should also note that the digital agriculture rural development of our country is also facing many problems, mainly have the following questions: the core key development lagging behind, low level of autonomous sensor, the lack of dedicated chip, intelligent equipment, research and development of artificial intelligence has just started; The integration and sharing of data resources has not made substantial progress; The use of modern information technology to solve the practical problems in the agricultural industry is not obvious, especially the production link is weak; Agricultural digital economy significantly lags behind the secondary and tertiary industries. [1]According to statistics, in 2018, agricultural digital economy only accounted for $7.3 \%$ of agricultural added value, much lower than the $18.3 \%$ of industry and $35.9 \%$ of service industry[2]. The accuracy and universality of information services need to be improved.

The development of digital agriculture in Japan started earlier. Combined with the practice of Japan, the development of digital agriculture in China needs to pay attention to the following aspects: high yield, high efficiency, and promote green and sustainable development of agriculture; Using Beidou navigation, intelligent agricultural machinery, 5G network, etc., to achieve precision unmanned operations, improve the efficiency of agricultural machinery; The use of blockchain, big data and cloud platform to provide consumers with accurate production, processing and distribution of data information, so that consumers can buy at ease, eat safely; The use of agricultural robots, the labor force from the hard, dangerous work to liberate, realize the unmanned agricultural operations, automation, light simplification; Big data and artificial intelligence will be used to digitize experience, knowledge and technology to realize intelligent production and lower the threshold of agricultural employment.
Agricultural digitalization refers to the process of collecting agricultural elements and agricultural models by various information and communication technologies such as remote sensing, global positioning system, sensors, unmanned aerial vehicles, cloud computing and edge computing and converting them into binary digits that can be processed by computers. environmental factors (such as air temperature and humidity, light intensity and wind direction), technology factors and social and economic factors (e.g., price and demand for agricultural products); Agricultural model refers to the internal and external relations between agricultural processes, such as the growth rules of crops, the relationship between the amount of fertilizer applied and the yield, and the relationship between the yield and the price of agricultural products, which often belong to the existing agricultural knowledge and the experience of agriculture-related experts and technicians $(\mathrm{Li}$ Hao et al., 2020).

\subsection{Paper Structure}

The plan, organization, implementation and control of agricultural production and service creation in the process of digitizing agricultural elements and processes and analyzing the digital resources generated by the new Internet of Things system are adopted as the basic support system. Its goal is to achieve the precision of agricultural input and output control, the obvious inheritance of agricultural knowledge and experience, the transparency of agricultural products trading process and the minimization of the negative impact of agriculture on the environment.

With emerging information and communication technology to the process of digital agricultural elements optimization of data acquisition part and equipment configuration, data transmission network and transmission path optimization design, data storage and computing resources reasonable allocation and so on all need the corresponding model and algorithm[2].At the same time, the existing agricultural knowledge and technical experience of agricultural experts should be transformed into models and algorithms that can be processed by computers. Secondly, after the set up new agricultural iot systems, agricultural state perceived and real-time transmission to the data processing center, as the input of agricultural decision support system, need to go through and optimization model and algorithm of the recognition, judgment, determine if the regulation and control accuracy, and then output to the agriculture in the Internet of things system implementation. It can be seen that the data-driven model and algorithm is the core of the digital agricultural operation and management, and also the key to realize the intelligent agricultural decision support system. 


\section{BACKGROUND}

Firstly, through the information collection system of the Internet of Things covering the life cycle of agricultural products, a distributed accounting information chain based on the mechanism is formed from the whole process of production to sales. Each time for the quality traceability of specific agricultural products is based on the confidence verification and rule reasoning of stored data in the and associated data outside the chain, Then combined with the attributes of the network nodes themselves (such as the reputation of online platforms and the reputation of individual farmers, etc.), they are mapped into the trust network to build a trust chain running through the upstream and downstream members, and dynamically adjust and update the trust network[3]. This method, which takes "information chain, evidence chain and trust chain" as the main line, can quickly realize the trust analysis process of agricultural products traceability inquiry, evidential reasoning, confidence verification, trust fusion and so on, and provide new technology for solving the quality problems of agricultural products. RS (remote sensing), GIS (geographic information system), GIS (global positioning system), sensors, 5G, big data, cloud computing and other new generation of information technology is the core technology of digital agriculture. 3S technology, sensors, machine vision, etc., are widely used in crop yield estimation, growth monitoring, meteorological and pest prediction, fine fertilization and irrigation and other fields. Intelligent agricultural equipment is the key support conditions for the development of digital agriculture.For example, variable fertilization seeder, precision spraying equipment, farmland data mobile acquisition system, plant protection UAV, greenhouse automatic control system and so on have been applied in the actual production and the effect is good.

\subsection{Probabilistic Automata}

The mutual integration of 5G technology and basic common capabilities (artificial intelligence, Internet of Things, cloud computing, big data and edge computing) can provide basic conditions for the development and operation of $5 \mathrm{G}$ agricultural applications, and create real-time transmission conditions for the navigation, identification and control of agricultural robots, unmanned vehicles, unmanned ships and unmanned aerial vehicles[4]. Operators can operate and control remote agricultural equipment with $5 \mathrm{G}$ broadband and low delay capability. With the large connection capacity of $5 \mathrm{G}$, environmental information and device state information perceived by sensors are gathered and shared on the cloud computing platform. Through big data processing, decisions are made and optimized on the environment and equipment, and the results are presented on the terminal devices. $5 \mathrm{G}$ will provide the possibility for the implementation of unmanned farm, that is, the use of the Internet of Things, big data, artificial intelligence, $5 \mathrm{G}$, robots and other new generation of information technology, in the case of human do not enter the farm, through the facilities, It is an all-weather, whole-process, whole-space unmanned production operation mode to complete all production operations on the farm.

\section{CONCLUSION}

Within the digital agriculture continuously promote the development of the stage, has been in the digital background, in view of the actual conditions, in the field of agriculture to develop agriculture and big data, "cloud" computing, emerging technologies, such as new combination pattern, the pattern of development for the development of agriculture and income growth has played an important role, but to agriculture can continuous burst of energy, To create income, we should constantly understand the needs of the market on the basis of digital agriculture, further promote the development of agricultural industrialization, and achieve new breakthroughs in agricultural production development. First, we need to focus on key issues[5]. In the context of Internet technology and digital agriculture, big data and "cloud" computing have become the key links in the development of digital agriculture. If we want to further promote the development of agriculture, we must adhere to this center and key links and resolutely do not relax. We need to do the following. First, we need to follow the guidance of national policies, which is the prerequisite and foundation. Grasping the relevant national policies for agriculture is the premise of making full use of digital technology to develop agriculture. Second, realize the deep development of big data. Big data are reflected in social each domain, which to a certain extent reflect the contemporary master more information and data for the dominant position in the competition, the importance of and for agriculture, will continuously according to the change of agricultural production and the change of market demand, timely records and statistical analysis of data, and adjusted in time according to the change, In this way, the lag of information and data will not bring negative impact on the production and sales of products; Third, build a sharing economy. Sharing in recent years, the economic has walked into people's field of vision, put forward the concept also brought some opportunities for development, many enterprises seized the business opportunity, continuous development and innovation of new profit pattern, for example, Shared cycling. In the agricultural sector, we should also timely keep up with the changes of The Times, make full use of the development opportunities of the sharing economy, actively develop the sharing farm, sharing home 
stay and other industries, on the basis of agricultural production, drive the development of the secondary and tertiary industries, and promote the formation of the agricultural industry chain. Digital technology mainly includes remote sensing (RS), geographic information system (GIS), global positioning system (GPS), computer technology, communication and network technology, automation technology and the Internet of things and other high and new technology. Digital technology power transformation and upgrading of traditional agriculture as the digital agriculture, to realize in the process of agricultural production of crops, real-time monitoring of soil from macroscopic to microcosmic, to achieve on crops growth, development, plant diseases and insect pests, water conditions and access to information on a regular basis, the corresponding environment for generating dynamic spatial information system, to the agricultural production in the phenomenon, to simulate the process, To achieve the rational use of agricultural resources, reduce production costs, improve the ecological environment, improve crop products and quality of the purpose. First of all, the construction of digital service collaboration platform should be regarded as the core task. We will build a system that covers the entire ecosystem [6].Secondly, build a full coverage system for downstream customers and consumer groups.

\section{REFERENCES}

[1] Chen Chunliang. Experiences and Policy implications of facilities Agriculture Development in the Netherlands, Japan, Israel [J]. Policy Outlook, 2016 (9): 47-50.

[2] the University of Arizona Agricultural and Biosystems engineering. Total areas in major greenhouse production countries [EB / OL]. [2012-02-21] .http: r / ag.arizona.edu/ceac

[3] Ministry of Agriculture, Forestry and Fisheries. General situation, characteristics and trend Analysis of facilities Horticulture abroad [J]. Journal of Nanjing Agricultural University, 2012,35 (5): 43-52.

[4] Qin Liu. Experience and reference of the development of facility agriculture in foreign countries [J]. World Agriculture, 2015 (8): 143-146.

[5]Jin Bo, Qiao Xiaojun, Wang Cheng, et al. Design and implementation of greenhouse Environmental Information Voice prompt system [J]. Journal of Agricultural Engineering, 2004,20 (3): 209-211.

[6]Li Shijun, Guo Shirong. Facility horticulture [M]. China Agriculture Press, 2011.
[7] P. Xu, N. Na, A. M. Mohamad, Investigation the application of pristine graphdiyne (GDY) and boron-doped graphdiyne (BGDY) as an electronic sensor for detection of anticancer drug, Computational and Theoretical Chemistry, 1190(2020): 112996.

[8] P. Xu, N. Na, Study on Antibacterial Properties of Cellulose Acetate Seawater Desalination Reverse-Osmosis Membrane with Graphene Oxide, Journal of Coastal Research, 105(2020)246-251. 